\title{
TAXonomía
}

\section{PARA DETERMINAR}

la tipología del clúster de tecnologías de la información en Aguascalientes

\author{
Bogar García Martínez \\ Roberto González Acolt \\ Irery Lizbeth Melchor Durán \\ Universidad Autónoma de \\ Aguascalientes
}

RECIBIDO: 10 DE MAYO DE 2017 ACEPTADO: 28 DE AGOSTO DE 2017

\section{RESUMEN}

sta investigación tiene 4 como objetivo determinar la tipología del clúster de tecnologías de la información de Aguascalientes. Se aplicó una metodología cualitativa, la cual incluye una taxonomía desarrollada para identificar la tipología de los clústeres con base en las variables de estructura, gobierno y desempeño. Se aplicaron quince entrevistas altamente estructuradas a los miembros de la Cámara Nacional de la Industria Electrónica, de Telecomunicaciones y Tecnolo- gías de la Información (Canieti). Los resultados son que el clúster es de una tipología marshalliana y su contribución al desarrollo del estado de Aguascalientes será creciente, al integrarse en su mayoría por micro, pequeñas y medianas empresas (mipyme).

Palabras clave: tipología del clúster de tecnologías de la información, clúster de tecnologías de la información, taxonomía tipología del clúster.

\section{Abstract \\ This research aims to determine the typol- ogy of the Aguascali-}


entes information technology cluster. A qualitative methodology was applied which includes a taxonomy developed to identify the typology of clusters based on the variables of structure, government, and performance. Fifteen highly structured interviews were applied to the members of the Mexican Chamber of Electronics, Telecommunications, and Information Technologies (Canieti) in Aguascalientes. The results are that the cluster is of a Marshallian typology and its contribution to the development of the state of Aguascalientes will be increasing, because most of its members are micro, small, and medium enterprises (mipyme).

Keywords: Typology of information technology cluster, information technology cluster, cluster typology taxonomy.

\section{INTRODUCCIÓN}

unque existe un gran
potencial en los clús-
teres para impulsar la transformación de las industrias, no se ha investigado suficientemente su tipología, como se observa en la tabla 1 . Solo se encuentran investiga- ciones de la tipología de dos clústeres en Aguascalientes: automotriz y electrónico.

Las investigaciones arrojan que tanto el clúster automotriz como el clúster electrónico son de tipo satélite. Asimismo, determinar cada tipología arroja las características de las interacciones entre los agentes de cada clúster; por ejemplo, los rasgos más destacados del clúster automotriz y el clúster electrónico en Aguascalientes son:

- El $90 \%$ de las empresas que dominan estos sectores son de origen extranjero

- Las compañías locales son de tamaño pequeño y mediano

- Existe poco comercio dentro del clúster entre compradores y vendedores (García, González, \& Leal, 2012; García, Leal, \& Melchor, 2016)

El objetivo es determinar la tipología del clúster de tecnologías de la información en el estado de Aguascalientes, haciendo una contribución al acervo de conocimientos en relación con la dinámica económica regional.
El clúster de tecnologías de la información es de tipo marshalliano y, por lo tanto, está integrado por empresas pequeñas y medianas. Existen pocas economías de escala, pero hay mano de obra calificada; los trabajadores están comprometidos con el sector y no con una empresa; existe expertise en tecnologías de la información por parte de los propietarios de negocios y los trabajadores; y el clúster tiene una identidad local.

En este trabajo se presenta un eje teórico, se describe el método de trabajo, se hace un análisis e interpretación de los resultados, y se determinan las conclusiones.

\section{MarCo TEÓRICO}

n los años noventa, los
sectores productivos
de los países capitalistas estaban haciéndose más pequeños, debido a que las plantas de muchas compañías migraban a países en donde los costos eran más bajos. A causa de este fenómeno, se realizaron estudios sobre cómo los clústeres generaban sistemas cooperativos con empresas innovadoras, a través de las cuales se mantenía el sector 
Tabla 1. Tipología de dos clústeres en Aguascalientes.

\begin{tabular}{|c|c|c|c|}
\hline Clúster & Tipología & Rasgos principales & Fuente \\
\hline Automotriz & Satélite & $\begin{array}{l}\text { El 90\% de las empresas que dominan el clúster son de } \\
\text { origen extranjero y las empresas locales solo son peque- } \\
\text { ñas y medianas (pyme); existe poco comercio dentro } \\
\text { del clúster entre compradores y vendedores, entre otras } \\
\text { características }\end{array}$ & $\begin{array}{l}\text { García, Gon- } \\
\text { zález, \& Leal } \\
\text { (2012) }\end{array}$ \\
\hline Electrónico & Satélite & $\begin{array}{l}\text { El 90\% de las empresas que dominan el clúster son de } \\
\text { origen extranjero y las empresas locales solo son pyme; } \\
\text { existe poco comercio dentro del clúster entre comprado- } \\
\text { res y vendedores, entre otras características }\end{array}$ & $\begin{array}{l}\text { García, Leal, \& } \\
\text { Melchor (2016) }\end{array}$ \\
\hline
\end{tabular}

Fuente: Elaboración propia basada en García, González \& Leal (2012) y García, González \& Melchor (2016).

productivo en esta misma región. Fueron los nuevos distritos industriales (new industrial district), los cuales sobrevivían aun con la tendencia de reducción de fábricas en países como Estados Unidos para llevarlas a otros. Por mucho tiempo, los estudios se concentraron en este tipo de modelo de clústeres y, más tarde, se detectó que existían otros tipos de clústeres, los cuales tenían características muy distintas a los nuevos distritos industriales (Markusen, 1996).

En contraste con la situación por la que atravesaba Estados Unidos en esa época, en donde los sectores productivos se reducían, en el estado de Aguascalientes el gobierno fomentaba una estrategia de desarrollo económico a través de apoyar a diferentes clústeres, logrando atraer inversión extranjera y nutriendo diferentes clústeres de fábricas y empresas del sector (García, \& González, 2014).

Markusen (1996) indica que, además de los nuevos distritos industriales, existen otros tipos de clústeres dominados por el gobierno o corporativos multinacionales, en donde algunos clústeres en ciertas circunstancias y sectores son dirigidos de manera exógena, dejando al grupo de empresas sin posibilidad de influir en la mejora del desempeño del clúster.

El clúster es famoso porque se considera promotor del desarrollo económico; sin embargo, Barnes y Kaplinsky (2000), así como Vom Hofe y Chen (2006) aportan evidencia empírica de que el clúster no ha resultado ser para los países en desarrollo lo que los paradigmas económicos prometían. Cedillo, Piña y Noriega (2007), además de Unger y Chico (2004), identifican una problemática de supervivencia endeble para las empresas locales que son parte de los clústeres, sobre todo aquellos que son dirigidos de manera exógena.

\section{DEFINICIÓN DE CLÚSTER}

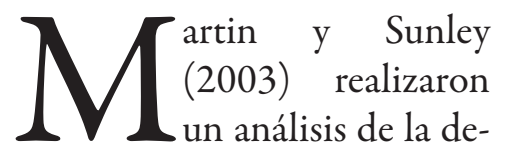
finición de clúster, planteando que existen contradicciones y confusiones en dos grandes áreas: la escala geográfica y la dinámica socioeconómica. Comentan que las definiciones de clúster son demasiado amplias y poco específicas, por lo que resultan imprecisas. $\mathrm{Al}$ no 
existir un consenso o unificación en la definición de clúster, es importante construir una que sea útil para el desarrollo del trabajo de investigación y el cumplimiento del objetivo, tal como lo sugiere Giuliani (2005).

Para Boja (2011), un clúster es un grupo de empresas que compiten y colaboran entre sí, mientras que García y González (2014) profundizan sobre el concepto al agregar que en un clúster, además de empresas, intervienen instituciones públicas y privadas de investigación y educación que pertenecen a un sector productivo específico. Lo más importante de su definición es que incluye el concepto de clúster como una unidad organizacional que evoluciona, es decir, un clúster es una entidad interactiva y cambiante; los tipos de clústeres que existen hoy en un estado, puede que no existan o cambien en un futuro.

De la teoría revisada, se incluye como base para determinar la tipología de los clústeres:

1) El modelo de Markusen (1996);
2) Las características de clasificación de Barkley y Henry (2003); y

3) Los factores de Boja (2011).

En la tabla 2 se muestran (integran) los diferentes componentes.

Existen otros modelos de tipología de clústeres; por ejemplo, Arikan y Schilling (2011) proponen un modelo basado en la estructura y el gobierno del clúster, sustentando el modelo básicamente en la centralización del control y en la necesidad de coordinación.

\section{TIPOS DE CLÚSTERES}

$\mathrm{M}$ arkusen agrupa los clústeres industriales en cuatro tipos, identificando sus rasgos básicos:

- Clúster industrial marshalliano;

- Clúster de empresas eje y sus componentes;

- Clúster satélite; y

- Clúster anclado al gobierno.

\section{Clúster industrial MARSHALLIANO}

D 1 clúster marshalliano se 1 caracteriza por una gran Lantidad de empresas pequeñas, las cuales compran y venden entre ellas. Aunque existen muy pocas economías de escala, el gran atractivo de este tipo de clústeres es la mano de obra calificada que se encuentra dentro del mismo; los trabajadores generalmente van de una compañía a otra, ya que los propietarios y ellos viven en la misma localidad; la dinámica del sector se vuelve constante, lo que permite crear una fuerte identidad cultural local, así como expertise industrial compartida; existen una serie de servicios especializados en líneas de productos, mercadotecnia, maquinaria, mantenimiento y reparación orientados a productos o industrias únicas. Los clústeres con estas características fueron muy estudiados, aunque muchos otros en el mundo no tenían estos rasgos (Markusen, 1996).

Clúster de empresas eje Y SUS COMPONENTES (HUBAND-SPOKE)

1 clúster de empresas eje $\checkmark$ y sus componentes es 1 una estructura empresarial dominada por una o varias empresas grandes, integradas verticalmente y rodeadas por proveedores; compañías principales integradas no local- 
Tabla 2. Tipología de clústeres.

\begin{tabular}{|c|c|c|c|}
\hline Tipos de clústeres & $\begin{array}{l}\text { Características de las } \\
\text { empresas (ESTRUC- } \\
\text { TURA) }\end{array}$ & $\begin{array}{l}\text { Interdependencia intraclús- } \\
\text { ter (GOBIERNO) }\end{array}$ & $\begin{array}{l}\text { Perspectiva de creci- } \\
\text { miento del empleo y } \\
\text { número de empresas } \\
\text { (DESEMPEÑ) }\end{array}$ \\
\hline $\begin{array}{l}\text { Marshalliano } \\
\text { (Marshallian) }\end{array}$ & $\begin{array}{l}\text { Pequeñas y medianas } \\
\text { empresas de propieta- } \\
\text { rios locales }\end{array}$ & $\begin{array}{l}\text { Intercambio de negocios y } \\
\text { colaboración sustancial en- } \\
\text { tre las empresas }\end{array}$ & $\begin{array}{l}\text { Dependiente de la } \\
\text { sinergia y la economía } \\
\text { provista por el clúster }\end{array}$ \\
\hline $\begin{array}{l}\text { Empresas eje y } \\
\text { sus proveedores } \\
\text { (bub-and-spoke } \\
\text { structure) }\end{array}$ & $\begin{array}{l}\text { Una o varias empresas } \\
\text { grandes con numero- } \\
\text { sos proveedores pe- } \\
\text { queños y empresas de } \\
\text { servicios }\end{array}$ & $\begin{array}{l}\text { Cooperación entre empre- } \\
\text { sas grandes y pequeños pro- } \\
\text { veedores en términos de las } \\
\text { grandes empresas }\end{array}$ & $\begin{array}{l}\text { Dependiente del creci- } \\
\text { miento de las grandes } \\
\text { empresas }(h u b)\end{array}$ \\
\hline $\begin{array}{l}\text { Plataformas sa- } \\
\text { telitales (satellite } \\
\text { platforms) }\end{array}$ & $\begin{array}{l}\text { Plantas medianas y } \\
\text { grandes del mismo } \\
\text { grupo empresarial } \\
\text { mundial }\end{array}$ & $\begin{array}{l}\text { Intercambio mínimo entre } \\
\text { empresas y redes }\end{array}$ & $\begin{array}{l}\text { Dependiente de la } \\
\text { habilidad de la región } \\
\text { para reclutar y retener } \\
\text { plantas del grupo em- } \\
\text { presarial }\end{array}$ \\
\hline $\begin{array}{l}\text { Ancladas al Estado } \\
\text { (State-anchored) }\end{array}$ & $\begin{array}{l}\text { Entidad pública o sin } \\
\text { fines de lucro, grande, } \\
\text { y compañías proveedo- } \\
\text { ras de servicios relacio- } \\
\text { nados }\end{array}$ & $\begin{array}{l}\text { Restricción a relaciones de } \\
\text { compraventa entre la enti- } \\
\text { dad pública y sus provee- } \\
\text { dores }\end{array}$ & $\begin{array}{l}\text { Depende de la habili- } \\
\text { dad de la región para } \\
\text { expandir el soporte } \\
\text { político para la realiza- } \\
\text { ción de obras públicas }\end{array}$ \\
\hline
\end{tabular}

Fuente: elaboración propia con base en Barkley y Henry (2003).

Figura 1. Clúster industrial marshalliano. Figura 2. Clúster de empresas eje y sus componentes.
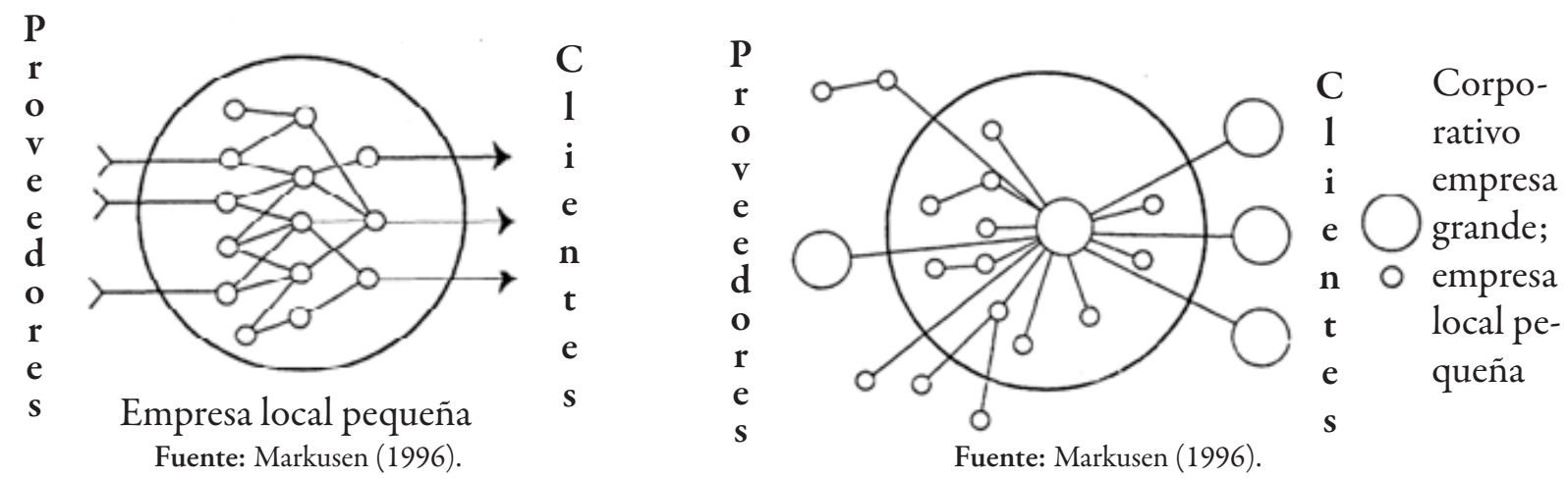
mente, ya que poseen fuertes vínculos con proveedores $\mathrm{y}$ competidores fuera del clúster; economías de escala relativamente altas; bajas tasas de rotación en las organizaciones locales, salvo en el tercer nivel; comercio sustancial dentro del distrito entre empresas dominantes y proveedores; decisiones clave de inversión tomadas de manera local, esparciéndose globalmente; compromisos y contratos a largo plazo entre compañías dominantes y proveedores; alto grado de cooperación; enlaces con organizaciones, tanto locales como externas; incidencia moderada de intercambios de personal entre clientes y proveedores; bajo grado de cooperación entre empresas competidoras grandes, para compartir el riesgo de estabilizar el mercado y generar innovación; mercado de trabajo menos flexible dentro del clúster; participación desproporcionada de obreros; trabajadores comprometidos, primero, con compañías grandes, después con el clúster $y$, posteriormente, con organizaciones pequeñas; tasas de inmigración de mano de obra mayores a las de emigración; evolución de vínculos de identidad de la cultura local; fuentes especializadas en finanzas, experiencia técnica y servicios para las empresas dominado por grandes compañías; baja disponibilidad de "capital de largo plazo" dentro del distrito, excluyendo a grandes organizaciones; ausencia de asociaciones de negocios proveedoras de infraestructura compartida; administración, entrenamiento, mercadotecnia, ayuda técnica y financiera; mecanismos de distribución de riesgos y estabilización; fuerte rol local del gobierno para promover y regular las industrias básicas en los niveles local, estatal y nacional; alto nivel de participación del gobierno al proveer infraestructura; crecimiento a largo plazo de la industria dependiente de las estrategias de las empresas dominantes (Markusen, 1996).

\section{Plataformas \\ INDUSTRIALES SATELITALES}

T os clústeres de plataformas industriales satelitales, se caracterizan por empresas grandes de origen extranjero, las cuales deciden invertir en una determinada zona geográfica; exis- te muy poca comercialización dentro del clúster, incluso, la comunicación entre los agentes del mismo, se hace a través de estas grandes compañías que invirtieron en la región; no hay compromisos a largo plazo con proveedores locales, debido a que las organizaciones grandes y extranjeras son controladas desde otros países y no operan compartiendo el riesgo, estabilizando el mercado o generando innovación; en ello, este tipo de clústeres difieren del de empresas eje y sus componentes en donde los grandes corporativos que dominan el clúster sí tienen una base local; existen altas tasas de inmigración y emigración laboral en los niveles gerenciales, profesionales y técnicos, así como tasas más bajas en los niveles de obreros y de apoyo; existe una compañía padre que toma todas las decisiones; el gobierno tiene un rol importante en la proveeduría de infraestructura, además de incentivos fiscales y otros de apoyo para los negocios (Markusen, 1996).

Clúster anclado al GOBIERNO

1 clúster anclado al go-
bierno es una estructu-
ra de negocios domi- 
Figura 3. Clúster satélite.

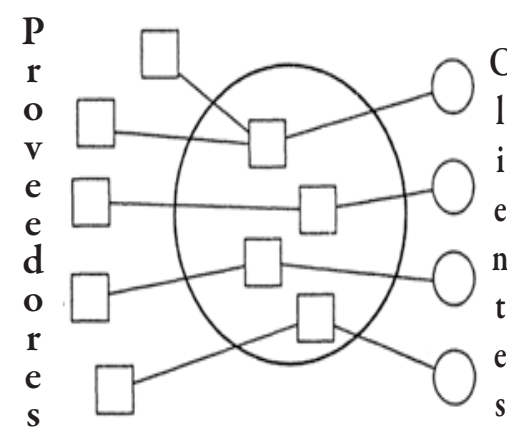

Fuente: Markusen (1996).
Figura 4. Clúster anclado al gobierno.

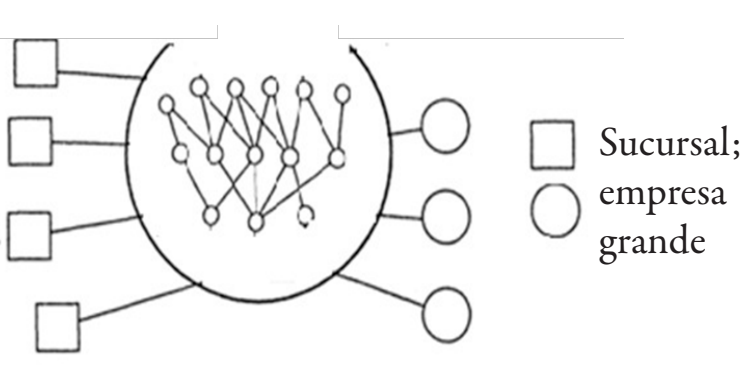

Empresa local pequeña

Fuente: Markusen (1996). nada por una o varias instituciones de gobierno, tales como bases militares federales o estatales y universidades públicas rodeadas por proveedores $\mathrm{y}$ consumidores (incluyendo las que están reguladas); economías de escala relativamente altas en el sector público; bajo grado de volumen de negocios locales; comercio sustancial entre instituciones dominantes y proveedores, pero no entre los demás miembros del clúster; decisiones sobre inversiones clave, se toman en varios niveles del gobierno: algunas son internas y otras, externas; compromisos a corto plazo entre proveedores e instituciones dominantes; alto grado de cooperación; enlaces con empresas exteriores para organizaciones de proveedores con sede externa; incidencia moderada en el cambio de personal entre consumidores y proveedores; bajo grado de cooperación entre compañías locales del sector privado para compartir riesgos, estabilizar el mercado y generar innovación; la fuerza de trabajo es interna si se trata del gobierno local y, nacional, si se trata del gobierno federal; existe una desproporción entre trabajadores técnicos y profesionales; trabajadores comprometidos, primero, con empresas grandes, después con el clúster y, finalmente, con organizaciones pequeñas; alto grado de inmigración del trabajo y bajo grado de emigración, a menos de que el gobierno esté cerran- do algún área; existe evolución en la identidad de la cultura local; no hay fuentes especializadas de apoyo financiero y técnico; no existe "capital de largo plazo" en el clúster; rol débil del gobierno al regular y promover actividades básicas; el gobierno se involucra en un alto grado para proveer infraestructura; las perspectivas a largo plazo para el crecimiento, dependen del panorama de obras del gobierno.

Para determinar si un clúster existente está o no dentro de una tipología determinada, se deberá evaluar conforme a las características de estructura, gobierno y desempeño del mismo (Markusen, 1996).

\section{Metodología}




\section{DESCRIPCIÓN DEL} PROBLEMA

$\mathrm{L}$ a dinámica económica de una región es el reentre los agentes que la conforman. El conocimiento de los tipos de clústeres dentro de un estado, aporta a los tomadores de decisiones información clave para el diseño de programas de desarrollo económico para potenciar el desempeño de las aglomeraciones de empresas. En Aguascalientes existe poca información sobre este tema, debido a que solo se cuenta con información de dos clústeres: el automotriz y el electrónico.

\section{JUSTIFICACIÓN}

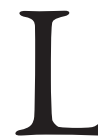

a riqueza de la información que arroja el determinar la tipología de cada clúster en un estado, radica en identificar la dinámica del medioambiente en el que se desenvuelve la empresa individual, la cual siempre es afectada por su entorno. $\mathrm{Si}$ funcionarios, empresarios, directores de centros de investigación e instituciones educativas cuentan con este conocimiento, podrán diseñar mejores estrategias para incrementar el desarrollo económi- co de una región; por ello, se ha decidido contribuir a esta serie de estudios determinando la tipología del clúster de tecnologías de la información en el estado de Aguascalientes.

\section{Pregunta de INVESTIGACIÓN}

- Cuál es la tipología del clúster de tecnologías de la información en Aguascalientes?

\section{OBJETIVO GENERAL}

on base en la taxonomía desarrollada clasificar la tipología del clúster de tecnologías de la información en el estado de Aguascalientes.

\section{Hipótesis}

C 1 clúster de tecnologías 4 de la información en Aguascalientes, es de tipo marshalliano.

\section{TIPO Y DISEÑO DE INVESTIGACIÓN}

T a investigación es cualitativa. El instrumento de recolección de datos es una entrevista altamente estructurada, que incluye una taxonomía desarrollada para identificar la tipología de los clústeres con base en las variables de estructura, gobierno y desempeño, identificando cuatro ítems para cada característica de las variables y donde se les asigna un valor del $1 \mathrm{al} 4$, en donde se obtiene la moda y se determina el tipo de clúster conforme a lo siguiente:

1) Corresponde al clúster marshalliano;

2) Corresponde al clúster de empresas eje y sus componentes;

3) Corresponde a una plataforma industrial satelital; $y$

4) Corresponde al clúster anclado al gobierno.

Como resultado del marco teórico, se diseñó un modelo de investigación en el que se muestra que la tipología del clúster se determina con base en las características de las variables de estructura, gobierno y desempeño del mismo; lo que da como resultado cuatro tipos de clústeres: marshalliano, empresas eje y sus componentes, satélite y anclado al gobierno (véase figura 5). Se realizó una taxonomía de todas las características de las variables considerando los diversos 
Figura 5. Modelo de investigación.

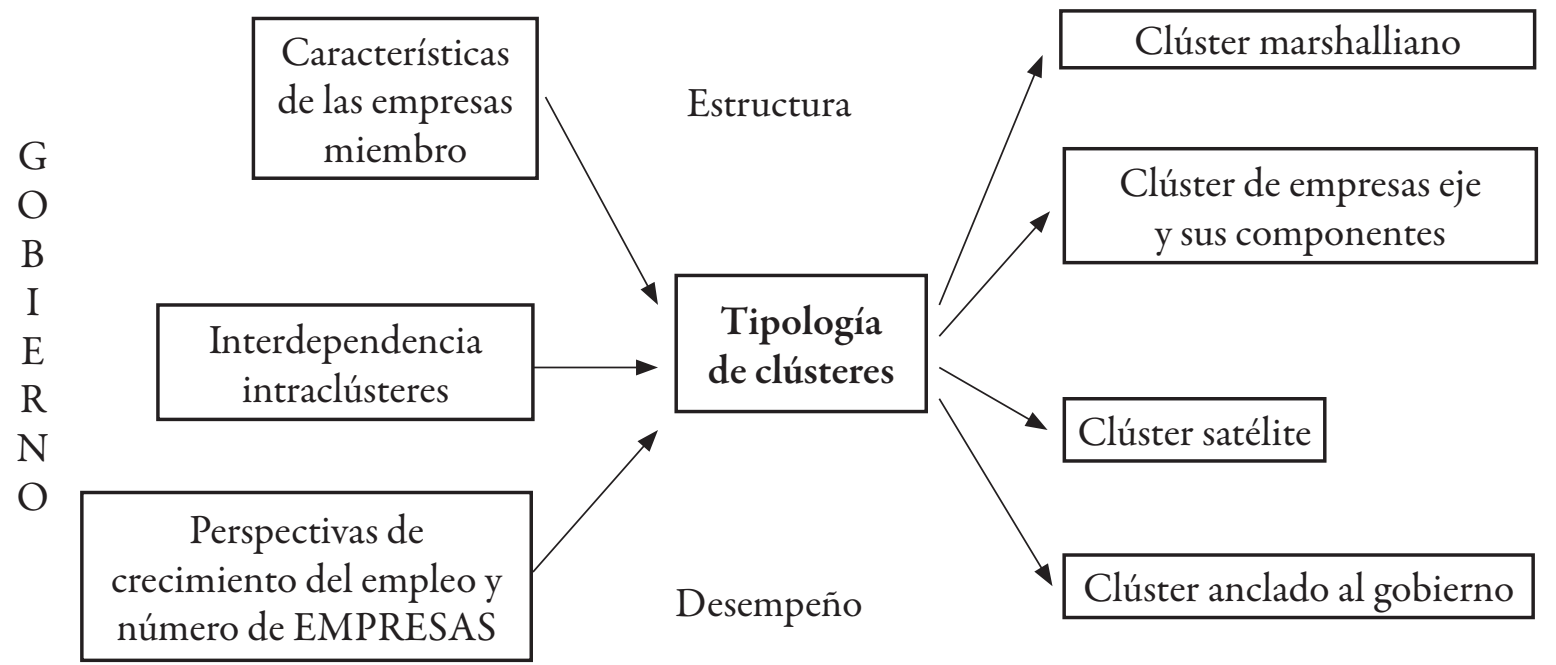

Fuente: García, González y Leal (2012).

autores consultados, integrándolas a cada uno de los cuatro tipos de clústeres. Con base en la taxonomía, se diseñó un instrumento de recolección de datos, una guía de entrevista altamente estructurada, la cual se aplicó a quince expertos en el sector de tecnologías de la información.

\section{Población y MUESTRA} DEL ESTUDIO

¿ $\begin{aligned} & \text { a población fueron } \\ & \text { cincuenta empresas } \\ & \text { dentro del padrón de la }\end{aligned}$
Cámara Nacional de la Industria Electrónica, de Telecomunicaciones y Tecnologías de la Información (Canieti). El criterio para seleccionar a las organizaciones entrevistadas fue que pertenecieran a la $\mathrm{Ca}$ nieti y pertenecieran al área de tecnologías de la información, donde quince de las cincuenta compañías cumplieron con este criterio y fueron entrevistadas. 


\section{Rua 16 \\ INSTRUMENTO DE RECOLECCIÓN DE DATOS}

Tabla 3. Guía de entrevista estructurada.

\begin{tabular}{|c|c|c|c|c|}
\hline $\begin{array}{l}\text { Tipos } \\
\text { de clús- } \\
\text { teres }\end{array}$ & Marshalliano & $\begin{array}{l}\text { Empresas eje y sus } \\
\text { componentes }\end{array}$ & $\begin{array}{l}\text { Plataformas sateli- } \\
\text { tales }\end{array}$ & Anclado al gobierno \\
\hline \multirow{5}{*}{ 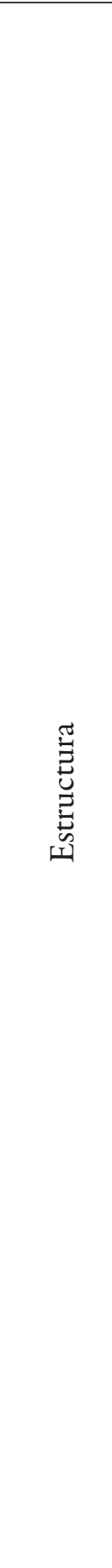 } & $\begin{array}{l}\text { Estructura de ne- } \\
\text { gocios dominada } \\
\text { por empresas loca- } \\
\text { les y pequeñas }\end{array}$ & $\begin{array}{l}\text { Estructura empresarial } \\
\text { dominada por una o } \\
\text { varias empresas gran- } \\
\text { des, integradas verti- } \\
\text { calmente y rodeadas } \\
\text { por proveedores A; } \\
\text { compañías principales } \\
\text { integradas no solo } \\
\text { localmente, ya que } \\
\text { poseen fuertes víncu- } \\
\text { los con proveedores } \\
\text { y competidores fuera } \\
\text { del clúster }\end{array}$ & $\begin{array}{l}\text { Estructura de nego- } \\
\text { cios dominada por } \\
\text { grandes empresas } \\
\text { de capital extranjero } \\
\text { con corporativos } \\
\text { con sedes externas }\end{array}$ & $\begin{array}{l}\text { Estructura de nego- } \\
\text { cios dominada por } \\
\text { una o varias institu- } \\
\text { ciones de gobierno, } \\
\text { tales como bases } \\
\text { militares federales o } \\
\text { estatales y universi- } \\
\text { dades públicas rodea- } \\
\text { das por proveedores } \\
\text { y consumidores } \\
\text { (incluyendo las que } \\
\text { están reguladas) }\end{array}$ \\
\hline & $\begin{array}{l}\text { Economías } \\
\text { de escala relativa- } \\
\text { mente bajas }\end{array}$ & $\begin{array}{l}\text { Economías } \\
\text { de escala relativamen- } \\
\text { te altas }\end{array}$ & $\begin{array}{l}\text { Economías } \\
\text { de escala de modera- } \\
\text { das a altas }\end{array}$ & $\begin{array}{l}\text { Economías } \\
\text { de escala relativa- } \\
\text { mente altas en el } \\
\text { sector público }\end{array}$ \\
\hline & $\begin{array}{l}\text { Intercambio sus- } \\
\text { tancial intraclúster } \\
\text { entre proveedores } \\
\text { y consumidores }\end{array}$ & $\begin{array}{l}\text { Comercio sustancial } \\
\text { dentro del distrito en- } \\
\text { tre compañías domi- } \\
\text { nantes y proveedores }\end{array}$ & $\begin{array}{l}\text { Mínimo comercio } \\
\text { dentro del clúster } \\
\text { entre compradores y } \\
\text { proveedores }\end{array}$ & $\begin{array}{l}\text { Bajo grado de vo- } \\
\text { lumen de negocios } \\
\text { para empresas } \\
\text { locales; comercio } \\
\text { sustancial entre insti- } \\
\text { tuciones dominantes } \\
\text { y proveedores, pero } \\
\text { no entre los demás } \\
\text { miembros del clúster }\end{array}$ \\
\hline & $\begin{array}{l}\text { Decisiones sobre } \\
\text { inversiones impor- } \\
\text { tantes tomadas de } \\
\text { manera local }\end{array}$ & $\begin{array}{l}\text { Decisiones clave de } \\
\text { inversión tomadas de } \\
\text { manera local, espar- } \\
\text { ciéndose globalmente }\end{array}$ & $\begin{array}{l}\text { Decisiones clave de } \\
\text { inversión tomadas } \\
\text { externamente }\end{array}$ & $\begin{array}{l}\text { Decisiones sobre } \\
\text { inversiones clave son } \\
\text { tomadas en varios } \\
\text { niveles del gobierno; } \\
\text { algunas son internas } \\
\text { y otras, externas }\end{array}$ \\
\hline & $\begin{array}{l}\text { Alta incidencia } \\
\text { de intercambio de } \\
\text { personal }\end{array}$ & $\begin{array}{l}\text { Incidencia moderada } \\
\text { en intercambio de } \\
\text { personal entre provee- } \\
\text { dores y clientes }\end{array}$ & $\begin{array}{l}\text { Alta incidencia en } \\
\text { intercambio de per- } \\
\text { sonal entre clientes } \\
\text { y proveedores exter- } \\
\text { namente, pero no a } \\
\text { nivel local }\end{array}$ & $\begin{array}{l}\text { Incidencia moderada } \\
\text { en intercambio de } \\
\text { personal entre pro- } \\
\text { veedores y consumi- } \\
\text { dores }\end{array}$ \\
\hline
\end{tabular}

Continúa... 


\begin{tabular}{|c|c|c|c|c|}
\hline $\begin{array}{l}\text { Tipos } \\
\text { de clús- } \\
\text { teres }\end{array}$ & Marshalliano & $\begin{array}{l}\text { Empresas eje y sus } \\
\text { componentes }\end{array}$ & $\begin{array}{l}\text { Plataformas sateli- } \\
\text { tales }\end{array}$ & Anclado al gobierno \\
\hline \multirow{5}{*}{ 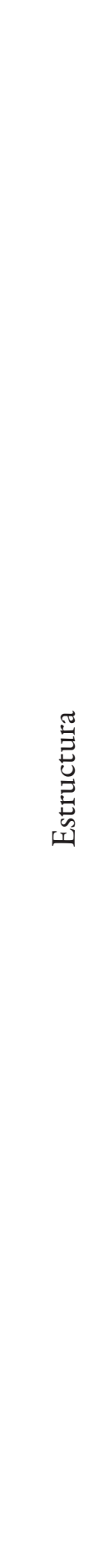 } & $\begin{array}{l}\text { Desproporción } \\
\text { entre trabajadores } \\
\text { técnicos y profe- } \\
\text { sionales }\end{array}$ & $\begin{array}{l}\text { Participación despro- } \\
\text { porcionada de obreros }\end{array}$ & $\begin{array}{l}\text { Participación des- } \\
\text { proporcionada de } \\
\text { obreros }\end{array}$ & $\begin{array}{l}\text { Desproporción entre } \\
\text { trabajadores técnicos } \\
\text { y profesionales }\end{array}$ \\
\hline & $\begin{array}{l}\text { Existencia de "ca- } \\
\text { pital de largo pla- } \\
\text { zo" en el distrito }\end{array}$ & $\begin{array}{l}\text { Baja disponibilidad de } \\
\text { "capital de largo pla- } \\
\text { zo" dentro del distrito, } \\
\text { excluyendo empresas } \\
\text { grandes }\end{array}$ & $\begin{array}{l}\text { No existe "capital } \\
\text { de largo plazo" en el } \\
\text { clúster }\end{array}$ & $\begin{array}{l}\text { No existe "capital } \\
\text { de largo plazo" en el } \\
\text { clúster }\end{array}$ \\
\hline & $\begin{array}{l}\text { Fuentes externas } \\
\text { especializadas en } \\
\text { servicios a empre- } \\
\text { sas en áreas finan- } \\
\text { cieras y técnicas } \\
\text { disponibles en el } \\
\text { clúster }\end{array}$ & $\begin{array}{l}\text { Fuentes especializadas } \\
\text { en finanzas, experien- } \\
\text { cia técnica y servicios } \\
\text { a empresas dominadas } \\
\text { por grandes empresas }\end{array}$ & $\begin{array}{l}\text { Principales fuentes } \\
\text { de finanzas, habi- } \\
\text { lidad técnica y de } \\
\text { servicios provistas } \\
\text { externamente me- } \\
\text { diante corporativos } \\
\text { o compras externas }\end{array}$ & $\begin{array}{l}\text { No existen fuentes } \\
\text { especializadas, de } \\
\text { apoyo financiero y } \\
\text { experiencia técnica } \\
\text { ni servicios de nego- } \\
\text { cios }\end{array}$ \\
\hline & $\begin{array}{l}\text { Amplia existencia } \\
\text { de asociaciones de } \\
\text { negocios }\end{array}$ & $\begin{array}{l}\text { Ausencia de asocia- } \\
\text { ciones de negocios } \\
\text { proveedoras de } \\
\text { infraestructura com- } \\
\text { partida, administra- } \\
\text { ción, entrenamiento, } \\
\text { mercadotecnia, ayuda } \\
\text { técnica y financiera, } \\
\text { mecanismos de dis- } \\
\text { tribución de riesgos y } \\
\text { estabilización }\end{array}$ & $\begin{array}{l}\text { No existen asocia- } \\
\text { ciones de negocios } \\
\text { que provean infraes- } \\
\text { tructura comparti- } \\
\text { da, administración, } \\
\text { entrenamiento, mer- } \\
\text { cadotecnia, ayuda } \\
\text { técnica y financiera, } \\
\text { mecanismos para } \\
\text { compartir riesgos y } \\
\text { estabilización }\end{array}$ & $\begin{array}{l}\text { Asociaciones de } \\
\text { negocios casi nulas } \\
\text { para compartir in- } \\
\text { formación del sector } \\
\text { público }\end{array}$ \\
\hline & $\begin{array}{l}\text { Mercado de tra- } \\
\text { bajo interno alta- } \\
\text { mente flexible para } \\
\text { el clúster }\end{array}$ & $\begin{array}{l}\text { Mercado de trabajo } \\
\text { menos flexible dentro } \\
\text { del clúster }\end{array}$ & $\begin{array}{l}\text { Mercado de mano } \\
\text { de obra externa al } \\
\text { clúster e integrado } \\
\text { verticalmente a las } \\
\text { empresas en el inte- } \\
\text { rior del mismo }\end{array}$ & $\begin{array}{l}\text { Fuerza de trabajo } \\
\text { interna: si se trata del } \\
\text { gobierno local; y na- } \\
\text { cional: si se trata de } \\
\text { una universidad, ins- } \\
\text { talaciones militares } \\
\text { u oficinas federales } \\
\text { para otros profe- } \\
\text { sionales, técnicos y } \\
\text { administradores }\end{array}$ \\
\hline
\end{tabular}

Continua... 


\section{Rua 18 的

\begin{tabular}{|c|c|}
\hline $\begin{array}{l}\text { Tipos } \\
\text { de clús- } \\
\text { teres }\end{array}$ & Marshalliano \\
\hline & $\begin{array}{l}\text { Contratos a largo } \\
\text { plazo y compro- } \\
\text { misos entre pro- } \\
\text { veedores locales y } \\
\text { compradores }\end{array}$ \\
\hline
\end{tabular}

Empresas eje y sus componentes

Compromisos y contratos a largo plazo entre empresas dominantes y proveedores

Ausencia de compromisos a largo

Compromisos a corplazo con proveedo- veedores e instituciores locales nes dominantes tales

Anclado al gobierno
Baja cooperación o vinculación con empresas externas al distrito
Alto grado de coo- peración; enlaces con empresas, tanto locales como externas; bajo grado de coope- ración entre empresas competidoras grandes para compartir el riesgo, estabilizar el mercado y generar innovación

Alto grado de coo-
peración; vínculos
con empresas exter-
nas, en especial con
la compañía padre;
bajo grado de coo-
peración entre em-
presas competidoras
para compartir el
riesgo, estabilizar el
mercado y generar
innovación

Trabajadores com-

Trabajadores comprometidos con el clúster en lugar de con la empresa prometidos, primero,

con empresas grandes;

después con el clúster

$\mathrm{y}$, posteriormente, con empresas pequeñas
Alto grado de cooperación; enlaces con empresas exteriores para organizaciones de proveedores con sede externa; bajo grado de cooperación entre empresas locales del sector privado, para compartir riesgos, estabilizar el mercado y generar innovación

Trabajadores comprometidos, primero,

Evolución de enlaces únicos de identidad de la cultura local

Evolución de vínculos de identidad de la cultura local

$$
\begin{aligned}
& \text { Fuerte rol local del } \\
& \text { gobierno para pro- }
\end{aligned}
$$

De baja a media la mover y regular las participación del industrias básicas, a gobierno para pro- niveles local, estatal mover y regular las y nacional; alto nivel industrias en la participación del gobierno al proveer infraestructura con grandes instituciones; después con los clústeres y, posteriormente, con empresas pequeñas

Mano de obra comprometida con la empresa y, posteriormente, con el clúster

Poca evolución en la Evolución en la idengeneración de lazos tidad de la cultura con la cultura local local
Rol débil del gobierno al regulary promover actividades básicas; el gobierno se involucra en un alto grado para proveer infraestructura 


\begin{tabular}{|c|c|c|}
\hline $\begin{array}{l}\text { Tipos } \\
\text { de clús- Marshalliano } \\
\text { teres }\end{array}$ & $\begin{array}{l}\text { Empresas eje y sus } \\
\text { componentes }\end{array}$ & $\begin{array}{l}\text { Plataformas sateli- } \\
\text { tales }\end{array}$ \\
\hline
\end{tabular}

Turbulencia, aunque buenas perspectivas a largo plazo para el crecimiento y el empleo
Crecimiento a largo plazo de la industria, dependiente de las perspectivas de la misma y las estrategias de empresas dominantes
El crecimiento se

pone en peligro por Perspectivas a largo la portabilidad de las plazo para el creciplantas en el media- miento, dependen no plazo hacia otros del panorama de lugares con platafor- obras del gobierno mas similares

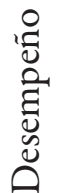

Altas tasas de inmigración laboral; bajos niveles de emigración
Bajas tasas de rotación en empresas locales, salvo en el tercer nivel de proveeduría; tasas de inmigración de mano de obra mayores a las de emigración
Tasas de rotación de personal de bajas a moderadas, excepto en el tercer nivel de proveeduría; altas tasas de inmigración y bajo grado de emiy emigración laboral gración, a menos de en niveles gerencia- que el gobierno esté les, profesionales y cerrando algún área técnicos; tasas más bajas en niveles de obreros y apoyo

Fuente: elaboración propia.

\section{ANÁlisis E \\ INTERPRETACIÓN DE RESULTADOS}

$\mathrm{L}$ a moda dentro de las características de estructura, gobierno $y$ desempeño del clúster de tecnologías de la información, es de 1 , la cual corresponde al clúster de tipo marshalliano, obteniendo una frecuencia de 53 de una serie de 68; por lo tanto, podemos decir que los rasgos del clúster de tecnologías de la información, se con- forman de los siguientes resultados por variable:

\section{ESTRUCTURA}

- Inversión necesaria (muy baja) para la creación de una empresa en el sector (\$2500 dólares)

- Estructura de negocios dominada por compañías locales y pequeñas

- Economías de escala relativamente bajas

- Intercambio sustancial intraclúster entre proveedores y consumidores
- Decisiones sobre inversiones importantes tomadas de manera local

- Alta incidencia de intercambio de personal

- Desproporción entre trabajadores técnicos y profesionales

- Existencia de "capital de largo plazo" en el distrito

- Fuentes externas especializadas en servicios a corporaciones (áreas financieras y técnicas) disponibles en el clúster 
- Amplia existencia de asociaciones de negocios

- Mercado de trabajo interno altamente flexible para el clúster

\section{GobIERNo}

- Contratos a largo plazo y compromisos entre proveedores locales y compradores

- Baja cooperación o vinculación con empresas externas al distrito

- Trabajadores comprometidos con el clúster en lugar de con la organización

- Evolución de enlaces únicos de identidad de la cultura local

- Participación del gobierno (de baja a media) para promover y regular las industrias

\section{DESEMPEÑo}

- Turbulencia, aunque buenas perspectivas a largo plazo para el crecimiento y el empleo

- Altas tasas de inmigración laboral y bajos niveles de emigración

\section{Conclusiones}

n las entrevistas se ob-
servan los siguientes
aspectos que pudieran ser considerados para el desa- rrollo de la política económica del Estado:

El Gobierno del Estado ha concentrado los recursos en la industria automotriz, la cual es un clúster tipo satélite que no genera encadenamientos locales con cadenas productivas importantes, además de que es portable y se puede ir en cualquier momento, ya que las decisiones se toman en corporativos en otros países cuyos intereses son empresariales. $\mathrm{Al}$ considerar lo anterior, un cambio de política económica hacia el apoyo al clúster de tecnologías de la información como prioridad aportaría más beneficios al Estado.

El clúster, al ser marshalliano, implica un desarrollo económico al integrarse a cadenas productivas locales y tener buenas perspectivas de crecimiento y empleo; cruza horizontalmente todos los clústeres, siendo un ente soporte del crecimiento y desarrollo de la economía del Estado, por lo que la inversión en este clúster manifiesta beneficios en el crecimiento económico de aquel. Es prioritario generar un ecosistema de negocios que tenga como eje el clúster de tecnologías de la información.
Generar un ecosistema teniendo como eje al clúster de tecnologías de la información, implica desarrollarlo en tres aspectos: estructura, gobierno y desempeño, integrando en estas variables al Gobierno del Estado, universidades y entidades de investigación, logrando así una triple hélice.

\section{REFERENCIAS}

BIBLIOGRÁFICAS

Arikan, A. T., \& Schilling, M. A. (2011). Structure and Governance in Industrial Districts: Implications for Competitive Advantage. Journal of Management Studies, 48(4), 772-803.

Barkley, D. L., \& Henry, M. S. (2003). Are Industry Clusters a Good Bet for Rural Development? South Carolina: Clemson University, Regional Economic Development Research Laboratory.

Barnes, J., \&. Kaplinsky, R. (2000). Globalization and the Death of the Local Firm? The Automobile Components Sector in South Africa. Regional Studies, 34(9), 797-812.

Boja, C. (2011). IT Clusters as a Special Type of Indus- 
trial Clusters. Informaticâ Economicâ,15(2), 184-193. Cedillo-Campos, M. G., PiñaMonárrez, M. R., \& Noriega-Morales, S. A. (2007). Hybrid Supply Chains in Emerging Industrial Countries: The Case of the Mexican Auto Industry. The $12^{\text {th }}$ Annual International Conference on Industrial Engineering Theory, Applications \& Practice, November 4-7, pp. 794-800.

Flores Preciado, J., Tene, R. H. , Vega Campos, M. Á,, \& Reyes Fong, T. (Eds.). Investigaciones en la gestión de las ciencias administrativas, competitividad y finanzas (pp. 53-68). México: Gasca.

García Martínez, B., \& González Acolt, R. (2014). El clúster automotriz en Aguascalientes: variables determinantes de su desarrollo. Zacatecas, México: Universidad Autónoma de Zacatecas.

García Martínez, B., González Acolt, R., \& Leal Medina, F. J. S. (2012). Modelo de tipología de clústeres: aplicación al clúster automotriz en Aguascalientes. IV
Congreso Internacional de Competitividad.

García Martínez, B., Leal Medina, F. J. S., \& Melchor Durán, I. L. (2016). Tipología del clúster electrónico en Aguascalientes.

Giuliani, E. (2005). The Structure of Cluster Knowledge Networks: Uneven and Selective, not Pervasive and Collective. DRUID Tenth Anniversary Summer Conference on Dynamics of Industry and Innovation: Organizations, Networks and Systems (pp. 1-20).

Markusen, A. (1996). Sticky Places in Slippery Space: a Tipology of Industrial Districts. Economic Geography, 72(3), 293-313.

Martin, R., \& Sunley, P. (2003). Deconstructing Clusters: Chaotic Concept or Policy Panacea? Journal of Economic Geography, 3(1), 5-35.

Unger Rubín, K., \& Chico Pérez, R. (2004). La industria automotriz en tres regiones de México: un análisis de clústeres. El Trimestre Económico, LXXI(284), 909941.
Vom Hofe, R., \& Chen, K. (2006). Whither or Not Industrial Cluster: Conclusions or Confusions? The Industrial Geographer, 4(1), 2-28. 